\title{
The effects of neem [Azadirachta indica A. Juss (meliaceae)] oil on Fusarium oxysporum f. sp. medicagenis and Fusarium subglutinans and the production of fusaric acid toxin
}

\author{
Marcia Regina Ferreira Geraldo ${ }^{1}$, Carla Cristina Arroteia ${ }^{2}$, Carlos Kemmelmeier ${ }^{2, *}$ \\ ${ }^{1}$ Universidade Tecnológica Federal do Paraná, Campo Mourão, Brazil; \\ ${ }^{2}$ Departamento de Bioquímica, Universidade Estadual de Maringá, Avenida Colombo, Maringá, Brazil. \\ Email: ccarroteia@uem.br; ckemmelmeier@uem.br; mperdoncini@ibest.com.br
}

Received 25 February 2010; revised 8 March 2010; accepted 10 March 2010.

\begin{abstract}
Fungi of the genus Fusarium are well known plant pathogens, cause several vascular diseases and are producers of toxins. In vitro assays evaluated the effects of Neem (Azadirachta indica) oil on the diameter of colonies, dry weight, spore production, spore viability and production of Fusaric Acid toxin on Fusarium oxysporum f. sp. medicagenis and Fusarium subglutinans isolates. Effects of Neem oil were analyzed at concentrations $0.25 \%, 0.5 \%$ and $1 \%$ in Czapek Yeast Agar medium. The production of Fusaric acid was determined by Thin Layer Chromatography and quantified by UV spectrophotometry. Neem oil showed inhibitory effects on the isolates tested, although they varied according to type of isolate and oil concentration. Neem oil was efficient in reducing the colonies' diameter and dry weight in concentration-dependent manner. Neem oil was efficacious at higher concentration in the decrease of sporulation. Spore germination was affected by Neem oil when the spore was grown in Neem-contained medium as when the spore emerged from a culture in a Neem medium. Neem oil decreased and even inhibited the production of Fusaric acid by the assayed isolates. Since these isolates are plant pathogens and producers of Fusaric acid, Neem oil may be introduced as an integral item in the management of host plants.
\end{abstract}

Keywords: Fusarium; Azadirachta Indica; Fusaric Acid; Antifungal Activity

\section{INTRODUCTION}

Fungi of the genus Fusarium, known to be plant pathogens causing several vascular diseases, are largely distributed in soils, especially cultivated ones, and are active during the decomposition of cellulose material [1].
Fusarium spp. is the main colonizer of pre-harvest cereal grains, even though it may also occur in grain storage, especially under high humidity conditions [2]. Fusarium oxysporum f. sp. medicagenis is a important pathogen for alfafa (Medicago sativa L.), whereas Fusarium moniliforme f. sp. subglutinans $=$ Fusarium subglutinans $[3,4]$ is a pathogen for maize, sugarcane and other grasses.The above mentioned fungi are producers of mycotoxins with special reference to fusaric acid (5butylpicolinic acid), which has a hypotension effect in several animals due to an increase in dopamine in the brain and to other peripheral effects in the tryptophan metabolism $[5,6]$. It not only interferes with animal food consumption, but also increases the toxicity of other mycotoxins [7]. Expectedly, the mycotoxin is rarely found alone in Fusarium-contaminated grains. This fact increases its importance in mycotoxicoses since this condition heightens the Fusaric acid's interactivity with other toxins, such as fumonisins and moniliformin [8,9]. Fusaric acid was one of the first fungus metabolites isolated from plants with Fusarium wilt and subsequently shown to be involved in the symptoms [9]. It is currently known to cause phytotoxic symptoms in several plants that develop Fusarium wilt. There are positive correlations between the production of the compound and the fungus virulence in the host [10]. Studies with several Fusaric acid-treated plants revealed that it inhibited respiratory activities [11-13]; decreased levels of adenosine triphosphate, increased the release of electrolytes [13], caused changes in the difference of transmembrane electrical potential [14]; disturbed nitrogen metabolism, decreased cell viability and induced apoptosis [12]; inhibited enzyme activities of plant defense [15-17]; induced plant's symptoms such as chlorosis, necrosis, inhibition and lengthening of roots $[18,19]$; and caused loss of weight in the plant [20].

Inhibiting chemical agents, mainly low molecular weight organic acids used in the preservation of stored grains [21], have exhibited several problems related to 
the development of fungus resistance and the emergence of secondary pests owing to their indiscriminate use [22]. This fact has increased risks of high toxic residue levels, which damage the environment and put human and animal health at risk. Plants' natural extracts may be an alternative for the employment of these synthetic antifungal chemical agents since they may be easily acquired and employed, they are low cost and lack the problems inherent to synthetic chemical products [23].

The Neem (Azadirachta indica A. Juss) is a denseleaved tree of the Meliaceae family whose biologically active extracts are obtained from its leaves, seeds, fruits and trunk, with acknowledged multiple therapeutic, insecticide, nematicide, anti-microbial and fungicide qualities [24-26]. Several studies show that Neem water and oil extracts are toxic to fungi [27-31] and may result in the reduction or inhibition of mycotoxin production [32-36]. Great interest exists in verifying the effects of the plant's extract on the fungi Fusarium oxysporum $\mathrm{f}$. sp. medicagenis and Fusarium subglutinans, due to the fact that if there is an inhibitory activity, the extract may be tested in host plants for the control of this pathogen. This is the main purpose of the present study.

\section{MATERIAL AND METHODS}

\subsection{Neem Oil}

Neem Oil (NO) was commercial product (BioNeem ${ }^{\circledR}$ ) extracted from the seeds of the neem plant.

\subsection{Fungal Isolates}

Isolates of Fusarium oxysporum f. sp. medicagenis UnB 201 and Fusarium subglutinans UnB 335 and UnB 327 were the test organisms used. They were stored in Potato Dextrose Agar (PDA) of the fungus collection at the Laboratory of Chemistry and Physiology of Microorganisms of the Biochemistry Department, State University of Maringá. Maringá. PR Brazil.

\subsection{Effects of NO on the Colony Diameter, Dry Weight, Sporulation and Spore Viability}

Assays were carried out according to technique described by Marques et al. [37]. Culture media employed were Malt Extract Agar (MEA) and Czapek Yeast Agar (CYA) [38]. CYA was prepared by adding $\mathrm{NO}$ to the medium to obtain concentrations of $0.25 \%, 0.5 \%$ and $1 \%$, which were the test media. CYA without NO was the control medium. Isolates were pre-incubated in MEA during four days, at $25^{\circ} \mathrm{C}$. Plugs were retrieved from these colonies by a $5 \mathrm{~mm}$-sterilized metallic ring and inoculated in $95 \mathrm{~mm}$-Petri dishes with media control CYA (without NO) and with CYA tests (with NO at concentrations $0.25 \%, 0.5 \%$ and $1.0 \%$ ).

Isolates were inoculated in media CYA control and tests at $25^{\circ} \mathrm{C}$, during seven days, to verify colonies' di- ameter. Colony's diameter was determined by measuring two diameters, in mm, of each colony on the seventh day of incubation.

Dry weight was determined after seven days of incubation of isolates, at $25^{\circ} \mathrm{C}$, in media CYA control and tests. Media were liquefied and mycelium was retrieved by a pincer and placed on a weighted filter paper. Papers with mycelia were dried at $70^{\circ} \mathrm{C}$. After $72 \mathrm{~h}$, they were weighted daily until completely dried.

Spores production was evaluated by placing $10 \mathrm{~mL}$ of a 1:1 mixture consisting of a sterilized solution $\mathrm{NaCl}$ $(0.89 \%, \mathrm{w} / \mathrm{v})$ and Tween $80 \AA(0.1 \%, \mathrm{v} / \mathrm{v})$, on the incubated mycelium, after 7 days, at $25^{\circ} \mathrm{C}$, in media CYA control and tests. After spores were removed by scraping all the mycelia, they were transferred to a test tube and counted under a microscope in a Neubauer chamber. Dilution of suspension was employed when required. Results were given in spores $/ \mathrm{mm}^{2}$ of colony. Spores viability (germination) was evaluated by their cultivation in cellophane membranes, previously cut $2 \mathrm{~cm} \times 2 \mathrm{~cm}$ size, dipped in distilled water in an Erlenmeyer flask and sterilized. Two situations were employed to verify spore viability: Experiment 1 - membranes were placed in CYA plates; each plate had one of the Neem oil concentrations mentioned above; they were then inoculated with spore suspensions from grown colonies in CYA without Neem oil, after incubation for four days, at 25 ${ }^{\circ} \mathrm{C}$; Experiment 2 - membranes were placed in plates with medium CYA without Neem oil. Inoculation was undertaken with spore suspensions from colonies grown in CYA with one of the different Neem oil concentration mentioned above, after incubation during four days, at $25^{\circ} \mathrm{C}$. Assays were undertaken by inoculating $0.1 \mathrm{~mL}$ of fungus suspension with $10^{5}$ spores $\mathrm{mL}^{-1}$ on each membrane. Plates with incubated membranes were then incubated at $25^{\circ} \mathrm{C}$, in the dark, during $15 \mathrm{~h}$. Drops of lactophenol cotton blue staining were then placed on grown membranes to impair germination and facilitate visualization of spores. By $400 \times$ microscope, 150 spores in each area of the lamina were counted. Germinated and non-germinated spores were counted and germination percentage established.

\subsection{Effects of Neem Oil on the Production of Fusaric Acid (FA)}

Assay was undertaken according to technique described by Eged [39]. Isolates were previously cultivated in MEA at $25^{\circ} \mathrm{C}$. After a four-day incubation, $5 \mathrm{~mm}$ diameter plugs of the culture were transferred to Petri plates with CYA control (without Neem oil extract) and tests (with $0.25 \%, 0.5 \%, 1.0 \%$ of Neem oil) and cultivated, during 7 days, within the same conditions. Media were liquefied after incubation and mycelia removed with a pincer. Liquefied medium was employed to extract FA since the mycotoxin is deposited in the extracellular me- 
dium by the fungus.

\subsection{Extraction and Quantification of FA}

Hydrochloric acid at $2 \mathrm{~N}$ was added to the medium to readjust $\mathrm{pH}$ to 3.9 - 4.0. Further, FA was extracted thrice with $30 \mathrm{~mL}$ of ethyl acetate in a separation funnel. The three extracts were put together and evaporated in a rotating evaporator at $50^{\circ} \mathrm{C}$, until complete dried. Residue was re-suspended in a $3 \mathrm{~mL}$ ethanol $80 \%$ water solution.

\subsection{Detection and Quantification of FA by Thin Layer Chromatography (TLC), and UV Spectrophotometry}

Basically the procedure described by Eged [39] was followed. In the case of TLC, $20 \times 20 \mathrm{~cm}$ aluminium plates (Alugram ${ }^{\circledR}$, Macherey-Nagel), coated with silica gel 60 (fluorescence indicator $\mathrm{UV}_{254}$ ) were employed. Plates were first dipped in a chromatography development solution (n-butanol : acetic acid : ethyl acetate : water $3: 2: 2: 2 \mathrm{v} / \mathrm{v}$ ), dried and activated at $80^{\circ} \mathrm{C}$ during 5-7 minutes. Further, $5-10 \mu \mathrm{L}$ of the standard solution of Fusaric acid $0.2 \%$ (Acros Organics $\left({ }^{\circledR}\right)$ and $30 \mu \mathrm{L}$ of the fungus residue extract solution were spotted on the activated TLC plate. After development $(R f=0.58-0.60)$, the plates were dried and observed under a $254 \mathrm{~nm}$ UV light. Sites with FA were cut from the plate and eluded with $3 \mathrm{~mL}$ ethanol liquid solution $80 \%$ (UV grade) during one hour. The contents of the FA in each sample were then determined by spectrophotometry $(\lambda 270 \mathrm{~nm}$ absorbance - UV-VIS spectrophotometer Shimadzu mini 1240, Japan).

Quantification of FA was undertaken according to standard calibration of FA (1 g Fusaric acid / 10 mL distilled water). Resulting quantity of FA was calculated according to the quantity of sample applied in the TLC plate in $\mu \mathrm{g}$ FA per gram of mycelial dry weight. All described experiments were carried out four times. Treatment results were evaluated statistically by one-way variance analysis (ANOVA), probability $1 \%(\mathrm{p}<0.01)$; in the case of significant difference, means were analyzed by Tukey's test ( $\mathrm{p} \leq 0.05)$, with the statistical program SAS (Statistical Analysis System. Sas Institute Inc., Cary, NC, USA, 2001).

\section{RESULTS AND DISCUSSION}

The effects of Neem Oil (NO) on the tested Fusarium isolates varied according to the isolate and NO concentrations (Table 1).

Neem oil was efficacious in reducing the diameter and dry weight in a concentration-dependent manner. Reduction of colonies' diameter occurred in all isolates: reduction was highest according to increase in oil concentration. In isolates $335 \mathrm{a}$ and 327 , NO reduced the dry weight at the lowest concentration $(0.25 \%)$. As NO con centration increased, the reduction of dry weight increased. Dry weight reduction in isolate 201 was effective in concentrations $0.5 \%$ and $1 \%$ of NO (Table 1 ).

$\mathrm{NO}$ at higher concentrations was efficient in sporulation decrease. The number of spores in isolates 201 and 335 a were lower only in an oil concentration of $1 \%$, but only statistically significant only for the isolate 327 . An increase in sporulation occurred at lower concentrations. Sporulation of isolate 327 was reduced as from oil concentrations at $0.5 \%$ (Table 1 ).

When spores were collected in colonies grown in a NO-less medium and germinated in a medium with different oil concentrations (Table 1-VS 1), germination of spores was significantly influenced only in concentration $1 \%$. Isolate $335 \mathrm{a}$ had its germination affected as from oil concentration $0.5 \%$. On the other hand, when spores obtained from media with different Neem concentrations and germinated in NO-less medium (Table 1-VS 2), spore viability was not affected in isolate 327 , which did not differ significantly from control. There was a decrease in spore viability in isolate $335 \mathrm{a}$ at all concentrations. This fact shows that spore germination is isolate-dependent and may be affected by NO either when the spore is grown in a medium with Neem or when the spore emerges in a medium with Neem. However, in the context of isolates tested in current assay (Table 1), the isolate 201 had the highest germination susceptibly to NO.

The production of Fusaric acid (FA) by the isolates (Table 1) was affected by NO Neem oil significantly reduced the production of FA, in proportion to oil concentration increase at all concentrations tested in isolate 327. Fusaric acid failed to be detected either in concentration $1 \%$ for isolate 327 or in all concentrations for isolate 335a. The latter, however, produced the lowest quantity of FA when compared to the other two isolates. Results show that NO may significantly reduce or even inhibit the production of FA by the isolates under analysis. Several assays with other fungi and toxins have shown similar results. Fungitoxic effects indicate that Neem extracts block the biosynthesis pathway of aflatoxin in Aspergillus parasiticus [31]; citrinin in Penicillium citrinum [35]; penicillic acid in Penicillium cycplopium [33]; patulin in Penicillium expansum in vitro [34] and in contaminated apples [32].

Although sporulation is typically followed by toxin production, its occurrence does not happen at all times. In fact, mycotoxins may be produced at high levels in growth conditions which inhibit sporulation [40]. In certain concentrations, as the current research showed, a sporulation stimulus occurred and, at the same time, a reduction in toxin production. Nevertheless, there was no relationship between sporulation and toxin inhibition 
Table 1. Effects of Neem oil (NO) in Fusarium oxysporum f. sp. medicagenis (201) and Fusarium subglutinans (327 and $335 \mathrm{a})$ isolates.

\begin{tabular}{|c|c|c|c|c|c|}
\hline Isolates & & Control & NO $0.25 \%$ & NO $0.5 \%$ & NO $1 \%$ \\
\hline \multirow{6}{*}{201} & Diameter & $82.5^{\mathrm{a}}( \pm 0.58)$ & $65^{\mathrm{b}}( \pm 1.15)$ & $57^{\mathrm{c}}( \pm 1.15)$ & $49.5^{\mathrm{d}}( \pm 0.58)$ \\
\hline & Dry weight & $0.063^{\mathrm{a}}( \pm 0.01)$ & $0.038^{\mathrm{ab}}( \pm 0.02)$ & $0.035^{\mathrm{b}}( \pm 0.01)$ & $0.018^{\mathrm{b}}( \pm 0.01)$ \\
\hline & $\mathrm{S}\left(\mathrm{x} 10^{4} / \mathrm{mm}^{2}\right)$ & $0.08374^{\mathrm{b}}( \pm 0.01)$ & $0.114525^{\mathrm{ab}}( \pm 0.01)$ & $0.128925^{\mathrm{a}}( \pm 0.02)$ & $0.07735^{\mathrm{b}}( \pm 0.02)$ \\
\hline & VS 1 (\%) & $93.77^{\mathrm{a}}( \pm 0.38)$ & $87.11^{\mathrm{a}}( \pm 3.44)$ & $86^{\mathrm{a}}( \pm 3.06)$ & $70.22^{\mathrm{b}}( \pm 3.95)$ \\
\hline & VS $2(\%)$ & $84.89^{\mathrm{a}}( \pm 4.44)$ & $48.88^{\mathrm{b}}( \pm 3.05)$ & $40^{\mathrm{b}}( \pm 2.40)$ & $37.33^{\mathrm{b}}( \pm 6.22)$ \\
\hline & FA & $24761.9^{\mathrm{a}}( \pm 35.24)$ & $22500^{\mathrm{b}}( \pm 44.74)$ & $21857.1^{\mathrm{b}}( \pm 41.43)$ & $8333.3^{\mathrm{c}}( \pm 33.33)$ \\
\hline \multirow{6}{*}{327} & Diameter & $76.25^{\mathrm{a}}( \pm 0.96)$ & $60^{\mathrm{b}}( \pm 1.41)$ & $57.5^{\mathrm{b}}( \pm 2.38)$ & $49.75^{\mathrm{c}}( \pm 1.26)$ \\
\hline & Dry weight & $0.087^{\mathrm{a}}( \pm 0.01)$ & $0.05^{\mathrm{b}}( \pm 0.03)$ & $0.02^{\mathrm{c}}( \pm 0.0001)$ & $0.013^{\mathrm{c}}( \pm 0.0002)$ \\
\hline & $\mathrm{S}\left(\mathrm{x10} / \mathrm{mm}^{2}\right)$ & $0.52145^{\mathrm{a}}( \pm 0.01)$ & $0.475925^{\mathrm{a}}( \pm 0.07)$ & $0.094405^{\mathrm{b}}( \pm 0.01)$ & $0.0463^{\mathrm{b}}( \pm 0.003)$ \\
\hline & VS $1(\%)$ & $89.55^{\mathrm{a}}( \pm 3.91)$ & $86^{\mathrm{ab}}( \pm 3.46)$ & $85.55^{\mathrm{ab}}( \pm 2.04)$ & $75.78^{\mathrm{b}}( \pm 3.05)$ \\
\hline & VS $2(\%)$ & $88.44^{\mathrm{a}}( \pm 3.01)$ & $87.55^{\mathrm{a}}( \pm 0.38)$ & $86.66^{\mathrm{a}}( \pm 0.67)$ & $85.33^{\mathrm{a}}( \pm 0.67)$ \\
\hline & FA & $25689.6^{\mathrm{a}}( \pm 34.48)$ & $15537.2^{\mathrm{b}}( \pm 37.47)$ & $11363.6^{\mathrm{c}}( \pm 39.09)$ & $\mathrm{Nd}$ \\
\hline \multirow{6}{*}{$335 a$} & Diameter & $83.25^{\mathrm{a}}( \pm 2.99)$ & $54.5^{\mathrm{b}}( \pm 2.38)$ & $45^{\mathrm{c}}( \pm 0.82)$ & $40.25^{\mathrm{c}}( \pm 1.71)$ \\
\hline & Dry weight & $0.15^{\mathrm{a}}( \pm 0.02)$ & $0.062^{\mathrm{b}}( \pm 0.06)$ & $0.047^{\mathrm{bc}}( \pm 0.03)$ & $0.012^{\mathrm{c}}( \pm 0.001)$ \\
\hline & $\mathrm{S}\left(\mathrm{x} 10^{4} / \mathrm{mm}^{2}\right)$ & $5.478^{\mathrm{b}}( \pm 0.89)$ & $8.2495^{\mathrm{a}}( \pm 0.29)$ & $7.572^{\mathrm{a}}( \pm 0.75)$ & $4.49675^{\mathrm{b}}( \pm 0.64)$ \\
\hline & VS $1(\%)$ & $97.77^{\mathrm{a}}( \pm 1.54)$ & $94.66^{\mathrm{a}}( \pm 1.33)$ & $81.11^{\mathrm{b}}( \pm 3.01)$ & $18.89^{\mathrm{c}}( \pm 1.02)$ \\
\hline & VS $2(\%)$ & $90.66^{\mathrm{a}}( \pm 0.38)$ & $84.44^{\mathrm{b}}( \pm 2.14)$ & $80.22^{\mathrm{b}}( \pm 1.02)$ & $79.55^{\mathrm{b}}( \pm 3.42$ \\
\hline & FA & $1900( \pm 20)$ & $\mathrm{Nd}$ & $\mathrm{Nd}$ & $\mathrm{Nd})$ \\
\hline
\end{tabular}

Details of experiment described in the section 'Materials and Methods'. Diameter of colony (mm); Dry Weight (g); S: Number of spores x104/mm² colony; FA: Fusaric Acid ( $\mu \mathrm{g} / \mathrm{g}$ dry weight); VS 1: Viability of spores (Experiment 1): germination percentage; VS 2: Viability of spores (Experiment 2): germination percentage; Nd: not detected. Means followed by the same small letter, on the line, do not differ among themselves by Tukey's test ( $\mathrm{p}$ $>0.05)$. All above described experiments were carried out four times. Values between parentheses: standard deviaton.

when the fungus grows in media with Neem. Strain 335a in the control medium had the highest number of spores and the lowest FA production. Initially it showed a sporulation stimulus in media with Neem but FA production was inhibited.

Neem extract's capacity in inhibiting growth and sporulation was variable among isolates. Inhibition in mycelial growth is generally associated with sporulation inhibition $[35,36]$. However, Neem extracts decreased or increased sporulation according to extract concentration without showing the same effect when associated with mycelial growth.

Significant reduction of the colonies' diameter, dry weight, number of spores, viability of spores and the production of FA depended on NO concentration, as current research showed. For the inhibition of FA synthesis, however, the experiments cannot rule out that this inhibition of FA synthesis is merely a result from the growth inhibitory effects. Neem extracts have fungitoxic activity, although their mode of action is not understood very well. It is quit possible that the different chemical or different ratios of chemicals found in the Neem trees have varied effects on fungi. Several studies have shown that NO produced high negative effects on Beauveria bassiana, with inhibition in germination, colony diameter and conidiogenesis [28]. Also some sort of inhibition with Neem extracts was reported on Phytophthora nicotianae, Aspergillus flavus and Aspergillus niger $[27,29,41]$.

Other researches reported antimicrobial activities from plant extract oils and showed inhibitory effects in the fungi tested, or rather; an increase in oil concentration produces an increase in inhibitory effects. Assays with essential oils confirm in vitro antifungal activity against Fusarium species [2,42].

Neem oil activities on the tested isolates show that the effects are concentration dependent and may vary according to the Fusarium species, fungal metabolisms, oil concentrations and anti-fungal activities.

Studies with oil from Neem seeds did not have any inhibitory effect on $F$. verticillioides [43], although it accelerated growth. On the other hand, complete inhibition of mycelial growth of Fusarium oxysporum f. sp. lycopersici was reported in a study with the dry extract of Neem seed in concentrations ranging from 5 to $30 \%$. There were no spores in Neem incorporated media [44].

The different effects of $\mathrm{NO}$ on mycelial diameter, sporulation, spore viability and toxin production should 
be attributed to Neem's active components and fungus metabolism. Although Azadiractin, known for its antifungus activities in in vivo and in vitro studies, may be isolated in small quantities from any part of the plant, mature seeds have the highest concentration of the compound [45].

The results of current research show that NO in the concentrations under analysis are effective on isolates of Fusarium oxysporum f. sp. medicagenis and Fusarium subglutinans. Since these isolates are plant pathogenic and producers of FA, further studies in vivo should be carried out with the same isolates and with host plants for the establishment of $\mathrm{NO}$ as an integral part of plant management.

\section{CONCLUSIONS}

The effects of Neem Oil extracts on growth, sporulation, morphology, and Fusaric acid production by Fusarum isolates were investigated. According to concentration, NO was efficacious in reducing the colonies' diameter, dry weight and sporulation. UV spectrophotometry analysis showed a reduction and even a complete inhibition of Fusaric acid production by using NO. The assays showed that NO has antifungal and anti toxin activity, even though their mode of action is not yet known. Evidence from the present and from other studies shows that fungal species react differently to compounds form the Neem oil. Additional research is needed to determine the potential usefulness of neem products in fungal control programs.

\section{ACKNOWLEDGEMENTS}

We would like to thank Dr. Thomas Bonnici for the grammatical review of the manuscript and to the Universidade Tecnológica Federal do Paraná for its support in this research.

\section{REFERENCES}

[1] Pitt, J.I. and Hocking, A.D. (1997) Fungi and food spoilage. 2nd Edition, Blackie Academic and Professional, London.

[2] Velutti, A., Marin, S., Gonzalez, P., Ramos, A.J. and Sanchis, V. ( 2004) Initial screening for inhibitory activity of essential oils on growth of Fusarium verticillioides, $F$. proliferatum and $F$. graminearum on maize-based agar media. Food Microbiology, 21, 649-656.

[3] Booth, C. (1971) The genus fusarium. Commonwealth Agricultural Bureaux, England.

[4] Seifert, K.A., et al. (2003) The name Fusarium moniliforme should no longer be used. Mycological Research, 107, 641-642.

[5] Porter, J.K., Bacon, C.W., Wray, E.M. and Hagler, W.M.J. (1995) Fusaric acid in Fusarium moniliforme cultures, corn, and feeds toxic and the neurochemical effects in the brain and pineal glands of rats. Natural Toxins, 3, 91-100.

[6] Hidaka, H. and Nagatsu, T. (1969) Fusaric acid, a hy- potensive agent produced by fungi. Journal of Antibiotics, 22, 228-230.

[7] Nagatsu, T., Hidaka, H., Kuzuya, H., Takeya, K., Umezawa, H., Takeuchi, T. and Suda, H. (1970) Inhibition of dopamine $\beta$-hydroxylase by fusaric acid (5-butylpicolinic acid) in vitro and in vivo. Biochemical Pharmacology, 19, 35-44.

[8] Bacon, C.W., Porter, J.K. and Norred, W.P. (1995) Toxic interaction of fumonisin $\mathrm{B}_{1}$ and fusaric acid measured by injection into fertile chicken egg. Mycopathology, 129, 29-35.

[9] Bacon, C.W., Porter, J.K., Norred, W.P. and Leslie, F. Production of fusaric acid by Fusarium species. Applied and Environmental Microbiology, 62, 4039-4043.

[10] Luz, J.M., Paterson, R.R.M. and Brayford, D. (1990) Fusaric acid and other metabolite production in Fusarium oxysporum f. sp. Vasinfectum. Letters in Applied Microbiology, 11, 141-144.

[11] Marrè, M.T., Vergani, P. and Albergoni, F.G. (1993) Relationship between fusaric acid uptake and its binding to cell structures by leaves of Egeria densa and its toxic effects on membrane permeability and respiration. Physiological and Molecular Plant Pathology, 42, 141-157.

[12] Samad, L. and Behboodi, B.S. (1985) Fusaric acid induces apoptosis in savron root tip cells: roles of caspase-like activity, cytochrome $c$ and $\mathrm{H}_{2} \mathrm{O}_{2}$. Planta, 225, 213-234.

[13] Arias, J.A. (1985) Secretory organelle and mitochondrial alterations induced by fusaric acid in root cells of Zea mays. Physiological and Plant Pathology, 27, 149-158.

[14] Bouizgarne, B., Brault, M., Pennarun, A.M., Rona, J.P., Ouhdouch, Y., El Hadrami, I. and Bouteau, F. (2004) Electrophysiological responses to fusaric acid of root hairs from seedlings of date palm-susceptible and -resistant to Fusarium oxysporum f. sp. Albedinis. Journal of Phytopathology, 152, 321-324.

[15] Curir, P., Guglieri, L., Dolci, M., Capponi, A. and Aurino, G. (2000) Fusaric acid production by Fusarium oxysporum f.sp. lilii and its role in the lily basal rot disease. European Journal of Plant Pathology, 106, 849-856.

[16] Wu, H.S., Yin, X.M., Zhu, Y.Y., Guo, S.W., Wu, C.L., Lu, Y.L. and Shen, Q.R. (2007) Nitrogen metabolism disorder in watermelon leaf caused by fusaric acid. Physiological and Molecular Plant Pathology, 71, 69-77.

[17] Kuzniak, E. (2001) Effects of fusaric acid on reactive oxygen species and antioxidants in tomato cell cultures. Journal of Phytopathology, 149, 575-582.

[18] Capasso, R., Evidente, A., Cutignano, A., Vurro, M., Zonno, M.C. and Bottalico, A. (1996) Fusaric and 9,10dehydrofusaric acids and their methyl esters from Fusarium nygamai. Phytochemistry, 41, 1035-1039.

[19] Barna, B. and Györgyi, B. (1992) Resistance of young versus old tobacco leaves to necrotrophs, fusaric acid, cell wall-degrading enzymes and autolysis of membrane lipids. Physiological and Molecular Plant Pathology, 40, 247-257.

[20] Gapillout, L., Milat, M.L. and Blein, J.P. (1996) Effects 
of fusaric acid on cells from tomato cultivars resistant or susceptible to Fusarium oxysporum f. sp. Lycopersici. European Journal of Plant Pathology, 102, 127-132.

[21] Chao, S.C., Young, D.G. and Oberg, C.J. (2000) Screening for inhibitory activity of essential oils on selected bacteria, fungi and viruses. Journal of Essential Oil Research, 12, 639-649.

[22] Cakir, A., Kordali, S., Kilic, H. and Kaya, E. (2005) Antifungal properties of essential oil and crude extracts of Hypericum linarioides Bosse. Biochemical Systematics and Ecology, 33, 245-256.

[23] Mossini, S.A.G. and Kemmelmeier, C. (2005) A árvore Nim (Azadirachta indica A. Juss): Múltiplos Usos. Acta Farmaceutica Bonaerense, 24, 139-148.

[24] Neves, B.P., Oliveira, I.P. and Nogueira, J.C.M. (2003) Cultivo e utilização do nim indiano. Embrapa Circular Técnica, 62, Goiás.

[25] Locke, J.C. (1995) Fungi, H., Ed. In Schmutterer, The Neem Tree. VHC, Weiheim, Germany, 118-126.

[26] Martinez, S.S. (2002) O Nim - Azadirachta indica. Natureza, Usos Múltiplos, Produção. Martinez, S.S., Ed., IAPAR, Londrina.

[27] Bowers, J.H. and Locke, J.C. (2004) Effect of formulated plant extracts and oils on population density of Phytophthora nicotianae in soil and control of phytophthora blight in the greenhouse. Plant Disease, 88, 11-16.

[28] Hirose, E., Neves, P.M.O.J., Zequi, J.A.C., Martins, L.H., Peralta, C.H. and Moino, A.J. (2001) Effect of biofertilizers and neem oil on the entomopathogenic fungi Beauveria bassiana (bals.) vuill and Metarhizium anisopliae (metsch.) sorok. Brazilian Archives of Biology and Technology, 44, 419-423.

[29] Krishnamurthy, Y.L. and Shashikala, J. (2006) Inhibition of aflatoxin $\mathrm{B}_{1}$ production of Aspergillus flavus, isolated from soybean seeds by certain natural plant products. Letters in Applied Microbiology, 43, 469-474.

[30] Razzaghi-Abyaneh, M., Allameh, A., Tiraihi, T., Ghahfarokhi, M.S. and Ghorbanian, M. (2005) Morphological alteration in toxigenic Aspergillus parasiticus exposed to neem (Azadirachta indica) leaf and seed aqueous extracts. Mycopathologia, 159, 565-570.

[31] Zeringue, H.J.J. and Bhatnagar, D. (1994) Effects of neem leaf volatiles on submerged cultures of aflatoxigenic Aspergillus parasiticus. Applied and Environmental Microbiology, 60, 3543-3547.

[32] Arrotéia, C.C., Kemmelmeier, C. and Machinski, J.M. (2007) Efeito dos extratos aquoso e oleoso de Nim [Azadirachta indica A. Juss (Meliaceae)] na produção de patulina em maçãs contaminadas por Penicillium expansum. Ciência Rural, 37, 1518-1523.

[33] Costa, C.L. and Kemmelmeier, C. (2008) Effect of aqueous and oily extracts from Neem [Azadirachta indica A. Juss (Meliaceae)] on the production of mycotox- ins by the polyketide pathway (penicillic acid and sterigmatocystin). Current Topics of Biotechnology, 4, $35-40$.

[34] Mossini, S.A.G., De Oliveira, K.P. and Kemmelmeier, C. (2004) Inhibition of patulin production by Penicillium expansum cultured with Neem (Azadirachta indica) Leaf Extracts. Journal of Basic Microbiology, 44,106-113.

[35] Mossini, S.A.G. and Kemmelmeier, C. (2008) Inhibition of citrinin production in Penicillium citrinum by Azadirachta indica A. Juss (Meliaceae) in culture. International Journal of Molecular Sciences, 9, 1676-1684.

[36] Mossini, S.A.G., Arrotéia, C.C. and Kemmelmeier, C. (2009) Effect of Neem leaf extract and Neem oil on Penicillium growth, sporulation, morphology and Ochratoxin A production. Toxins, 1, 2-13.

[37] Marques, R.P., Monteiro, A.C. and Pereira, G.T. (2004) Crescimento, esporulação e viabilidade de fungos entomopatogênicos em meios contendo diferentes concentrações do óleo de Nim (Azadirachta indica). Ciência Rural, 34, 1675-1680.

[38] Paterson, R.R.M. and Rutheford, M.A. (1991) A simplified rapid technique for fusaric acid detection in Fusarium strains. Mycopathologia, 113, 171-173.

[39] Eged, S. (2005) Thin-layer chromatography - an appropriate method for fusaric acid estimation. Biologia Bratislava, 60, 104.

[40] Adams, T.H. and Yu, J-H. (1998) Coordinate control of secondary metabolite production and asexual sporulation in Aspergillus nidulans. Current Opinion in Microbiology, 1, 674-677.

[41] Pawar, V.C. and Thaker, V.S. (2006) In vitro efficacy of 75 essential oils against Aspergillus niger. Mycoses, 49, 316-323.

[42] Soliman, K.M. and Badeaa, R.I. (2002) Effect of oil extract from some medicinal plants on different mycotoxigenic fungi. Food and Chemical Toxicology, 40, 16691675.

[43] Fandohan, P., Gbenou, J.D., Gnonlonfin, B., Hell, K., Marasas, W.F.O. and Wingfield, M.J. (2004) Effect of essential oils on the growth of Fusarium verticillioides and fumonisin contamination in corn. Journal of Agricultural and Food Chemistry, 52, 6824-6829.

[44] Agbenin, O.N. and Marley, P.S. (2006) In vitro assay of some plant extracts against Fusarium oxysporum f. sp. lycopersici causal agent of tomato wilt. Journal of Plant Protection Research, 46, 215-220.

[45] Schaaf, O., Jarvis, A.P., van der Esch, S.A., Giagnacovo, G. and Oldham, N.J. (2000) Rapid and sensitive analysis of azadirachtin and relate triterpenoids from neem (Azadirachta indica) by high performance liquid chromatography - tmospheric pressure chemical ionization mass spectrometry. Journal of Chromatrgraphy A, 886, 89-97. 